\title{
Histopathological study of thyroid lesions in a tertiary care center in coastal belt of South India
}

\author{
K.F. Magdalene ${ }^{1}$, Jose Swetha ${ }^{2}$, Navya Narayanan ${ }^{3}$, B Sumangala ${ }^{4}$ \\ ${ }^{1}$ Dr. K.F. Magdalene, Professor, ${ }^{2}$ Dr. Jose Swetha, Assistant Professor, ${ }^{3}$ Dr. Navya Narayanan O, Assistant Professor, \\ ${ }^{4}$ Dr. B Sumangala, Professor, All authors are affiliated with Pathology department, Sree Narayana Institute of Medical \\ Sciences, Chalaka, Kerala, India.
}

Address for Correspondence: Dr. K.F. Magdalene, magdalenekf@ gmail.com

\begin{abstract}
Introduction: Significant information regarding the lesions of thyroid can be obtained by histopatholological examination of the thyroidectomy specimens. Hence a scrupulous and methodical examination of the thyroidectomy specimens is needed. The aim of present study is to determine the prevalence of thyroid lesions in thyroidectomy specimens. Method: About 240 thyroidectomy specimens received in the pathology department between February 2010 to January 2016 were included in the study. The lesions were basically classified into non- neoplastic and neoplastic. Percentages and simple frequency tables were used for data analysis. Result: Out of the 240 thyroidectomy specimens $214(89.2 \%)$ were from females and $26(10.8 \%)$ were from males. The female: male ratio was 8.2:1. The age of the patients ranged from 2 to 83 years with a mean age of 44.6 years. 160 cases $(66.7 \%)$ cases were non-neoplastic and 80 cases $(33.3 \%)$ cases were neoplastic. The common non-neoplastic lesions were colloid goiter (101 cases; $42.1 \%)$ and Nodular Hashimoto thyroiditis (28 cases;11.7\%). There were 22 benign tumors and 58 malignant tumors. Follicular adenoma was the most common benign tumor (18cases, $7.5 \%$ ) and Papillary carcinoma was the most common malignant tumor (46 cases, 19.2\%). Conclusion: Neoplastic and non- neoplastic disorders affect thyroid gland. Most of the lesions are non- neoplastic. Colloid goiter was the most common non- neoplastic lesion. The most common benign tumor was Follicular adenoma and the most common malignant tumor was papillary carcinoma. This study differs from other studies by an increased incidence of Nodular Hashimoto thyroiditis.
\end{abstract}

Key words: Adenoma, Goiter, Neoplasm, Thyroiditis

\section{Introduction}

Thyroid gland has wide and vital physiological roles in the body. The thyroid hormones affect all body organs and are responsible for maintenance of homeostasis and the body integrity [1]. Thyroid disorders range from functional, immunological derangements to neoplastic lesions [2]. The etiology of thyroid nodule is multifactorial; iodine deficiency, radiation exposure, and dietary goitrogenic factors all play an important role in the pathogenesis of thyroid nodules [3].

The general population has an enormous burden of thyroid diseases. Among all the endocrine disorders, thyroid disorders are the most common in India [4]. In India, about 42 million people are affected by thyroid

Manuscript received: $24^{\text {th }}$ February 2017

Reviewed: $3^{\text {rd }}$ March 2017

Author Corrected: $10^{\text {th }}$ March 2017

Accepted for Publication: $15^{\text {th }}$ March 2017 diseases [5]. Coastal states like Gujarat, Goa, Kerala and hilly areas like Himalayan regions are endemic for thyroid lesions in India [6].

The main diseases of thyroid are simple goiter (diffuse and nodular), hyporthyroidism, hyperthyroidism, thyroiditis and neoplasms [7]. The prevalence of goitre differs according to the geographical region, age and $\operatorname{sex}[8]$.

Lesions affecting the thyroid can be accurately diagnosed by a careful histopatholological examination of thyroidectomy specimens.

This is a retrospective histopathological study of lesions affecting the thyroid, in the coastal belt of Central Kerala, South India. 


\section{Materials and Method}

A retrospective cross sectional study of thyroidectomy specimens was conducted at the department of Pathology, of Sree Narayana Institute of Medical Sciences, Kerala, India during the period from February $1^{\text {st }} 2010$ to January $31^{\text {st }} 2016$.

All patients presenting with thyroid enlargement, who underwent any type of thyroid operation (i.e.lobectomy, subtotal thyroidectomy, near total thyroidectomy or total thyroidectomy) were included in this study.

A total of 240 biopsy specimens of thyroid gland were selected for histopathological evaluation. Detailed information regarding age, gender, clinical status (hypothyroid, hyperthyroid or euthyroid), relevant investigations like fine needle aspiration cytology, thyroid scan, ultrasound reports and operation findings were obtained from histopathology request forms and register.
Paraffin-embedded blocks and the histopathology slides of all the thyroidectomy specimens received in the histopathology department were analyzed. The histopathology slides were retrieved from the archive and reviewed. The slides were prepared from the thyroidectomy specimens which were fixed in $10 \%$ formalin. Routine processing of representative areas were done after thorough grossing of the specimens. Paraffin embedded blocks were sectioned using microtome. The $5 \mu \mathrm{m}$ thick sections were stained with Haematoxylin and Eosin. The lesions were classified mainly into non- neoplastic and neoplastic.

The neoplastic lesions were classified based on the WHO histological classification of thyroid tumors [9]. The data thus collected was evaluated as percentages and simple frequency tables. The gross and microscopic photographs of relevant lesions were taken.

\section{Results}

A total of 240 thyroid specimens were received over the 6year period. There were $214(89.2 \%)$ females and $26(10.8 \%)$ males giving a female to male ratio of 8.2 :1.The overall age range was from 2 years to 83 years with a mean age of 44.6 years. The incidences of the various lesions with their percentage were studied [Table 1].

Table-1: Shows the incidence of the various lesions in thyroid with their percentage.

\begin{tabular}{|c|c|c|c|c|c|c|}
\hline $\begin{array}{l}\text { SL. } \\
\text { NO. }\end{array}$ & $\begin{array}{l}\text { Nature of } \\
\text { lesion }\end{array}$ & $\begin{array}{c}\text { No. of } \\
\text { cases (out } \\
\text { of 240) }\end{array}$ & $\begin{array}{l}\% \text { of } \\
\text { cases }\end{array}$ & Lesions & $\begin{array}{l}\text { Number of } \\
\text { lesions }\end{array}$ & $\%$ of lesions \\
\hline \multirow[t]{5}{*}{1.} & \multirow[t]{5}{*}{ Non neoplastic } & \multirow[t]{5}{*}{160} & \multirow[t]{5}{*}{66.7} & Nodular colloid goiter & 101 & 42.1 \\
\hline & & & & $\begin{array}{c}\text { Nodular Hashimoto } \\
\text { thyroiditis }\end{array}$ & 28 & 11.7 \\
\hline & & & & Hashimoto thyroiditis & 17 & 07.1 \\
\hline & & & & Thyroglossal cyst & 10 & 04.2 \\
\hline & & & & Lymphocytic thyroiditis & 04 & 01.7 \\
\hline \multirow[t]{7}{*}{2.} & \multirow[t]{7}{*}{ Neoplastic } & \multirow[t]{7}{*}{80} & \multirow[t]{7}{*}{33.3} & Papillary carcinoma & 46 & 19.2 \\
\hline & & & & Follicular adenoma & 18 & 07.50 \\
\hline & & & & Follicular carcinoma & 09 & 03.7 \\
\hline & & & & Hurtle cell adenoma & 04 & 01.7 \\
\hline & & & & Medullary carcinoma & 01 & 00.4 \\
\hline & & & & $\begin{array}{l}\text { Papillary carcinoma and } \\
\text { follicular adenoma }\end{array}$ & 01 & 00.4 \\
\hline & & & & $\begin{array}{l}\text { Papillary carcinoma and } \\
\text { Hurthle cell carcinoma }\end{array}$ & 01 & 00.4 \\
\hline
\end{tabular}

Colloid Goiter was the most common pathologic entity, constituting $42.1 \%$ of cases (101 cases out of 240). The average age of patient was 45 years. The age ranged from 21 to 83 years. 


\section{Research Article}

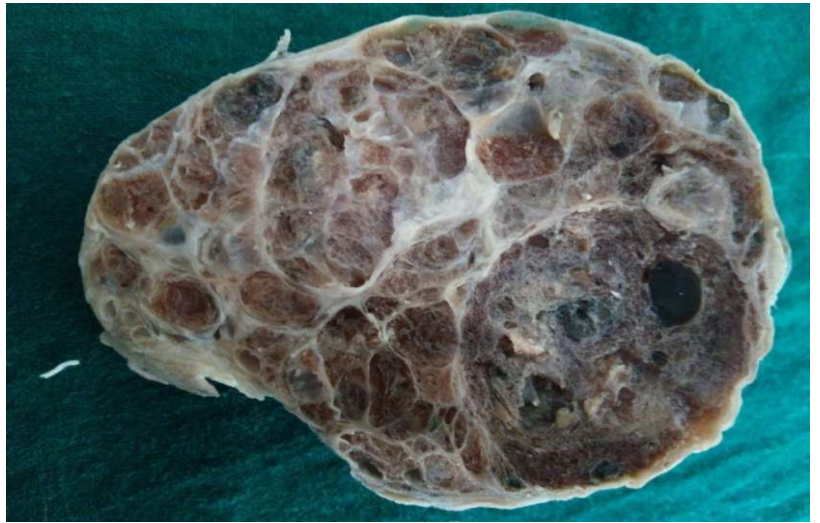

Fig.-1a: Gross specimen of multinodular goiter

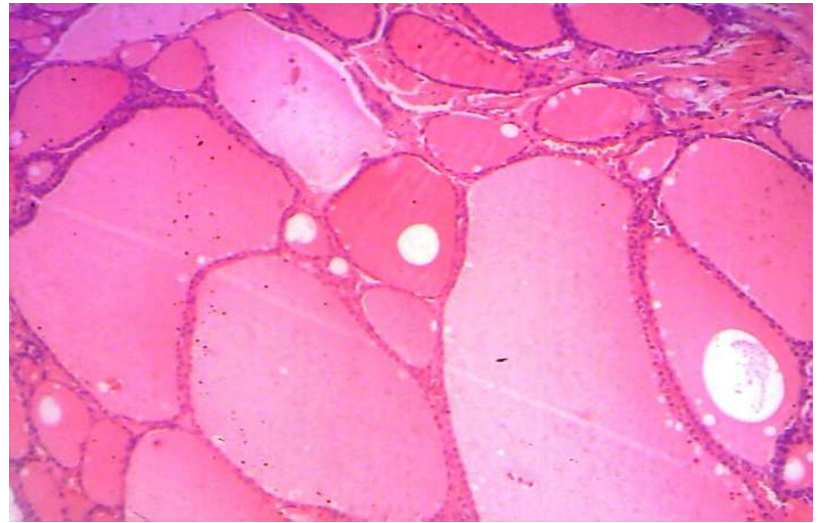

Fig- 1b: Section showing features of nodular colloid goiter with variably sized follicles containing colloid (Hematoxylin and Eosin $x$ 100x)

The second most common non- neoplastic condition was Nodular Hashimoto thyroiditis [Figure 2a, 2b]. The number of cases were 28 cases $(11.7 \%)$. This term is used when distinct nodularity is evident in Hashimoto thyroiditis. The epithelial components of the nodules have a hyperplastic quality.

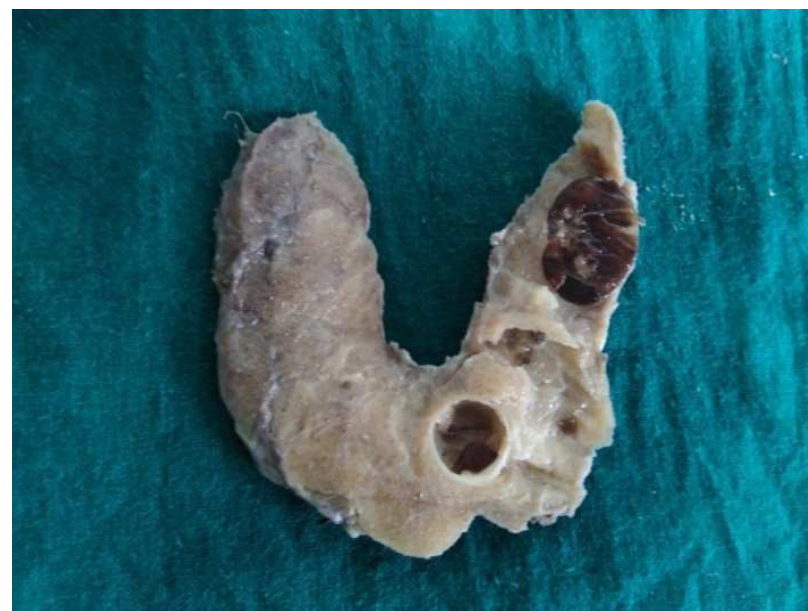

Fig- 2a: Gross specimen of Nodular Hashimoto thyroiditis

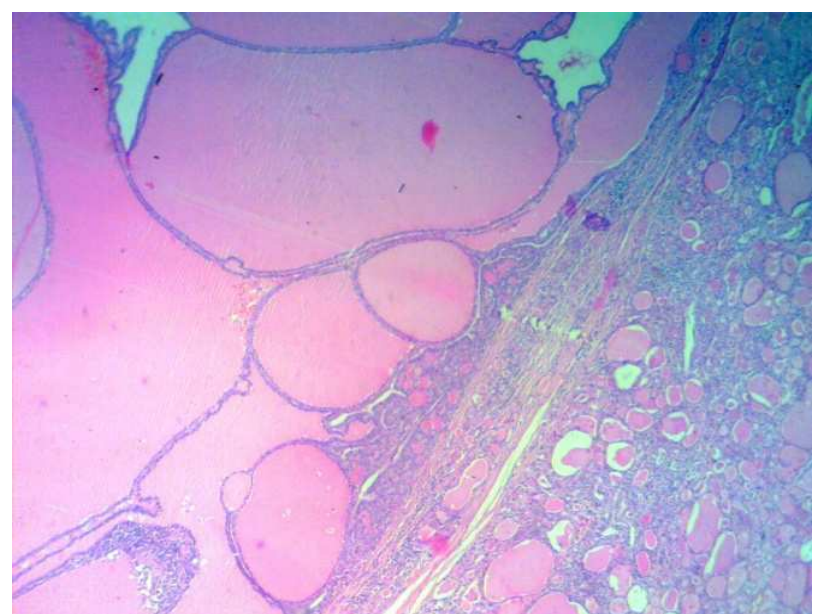

Fig-2b: Section showing Nodular Hashimoto thyroiditis with features of nodular hyperplasia [top, left] and Hashimoto thyroiditis [bottom, right]. ( Hematoxylin and Eosin $x$ 40x)

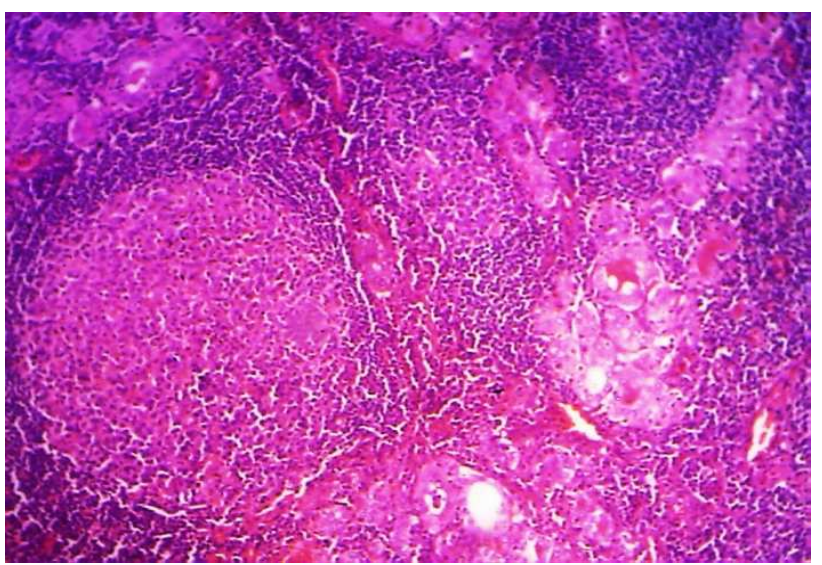

Fig-3b: Section showing features of Hashimoto thyroiditis with follicles lined by hurthle cells and lymphoid follicles having germinal centers. ( Hematoxylin and Eosin $\mathbf{x 1 0 0 x}$ ) 


\section{Research Article}

The third most common non-neoplastic cause was Hashimoto throiditis [Figure 3a,3b]. Hashimoto thyroiditis typically exhibits a diffuse appearance both grossly and microscopically. There were 17 cases $(07.1 \%)$. Microscopically, the two main abnormalities are lymphocytic infiltration of the stroma and oxyphilic change of the follicular epithelium. The average age of patients with Hashimoto thyroiditis was 44 .

The fourth most common non-neoplastic disorder was Thyroglossal cyst (10 cases; $04.2 \%$ ). The age group ranged from 2 to 46 years. The female to male ratio was $2: 3$ with a male preponderance. The additional findings noted were secondary inflammation, foreign body giant cell response and haemorrhage.

Four cases of chronic lymphocytic thyroiditis were detected. All were females. The age group ranged from 21 to 55 years. 2 cases showed focal Hurthle cell change.

The most common neoplastic disorder was Papillary carcinoma [Figure 4a, 4b]. 46 cases (19.2\%) were identified. The age group ranged from 18 to 66 years. The female to male ratio was 11.5:1. A single case of cribriform morular variant of papillary carcinoma was diagnosed [10]. A rare case of synchronous Hurthle cell carcinoma and papillary carcinoma with hashimoto thyroiditis detected, was documented [11]. Multicentricity was noted in 6 cases. One case had associated follicular adenoma.

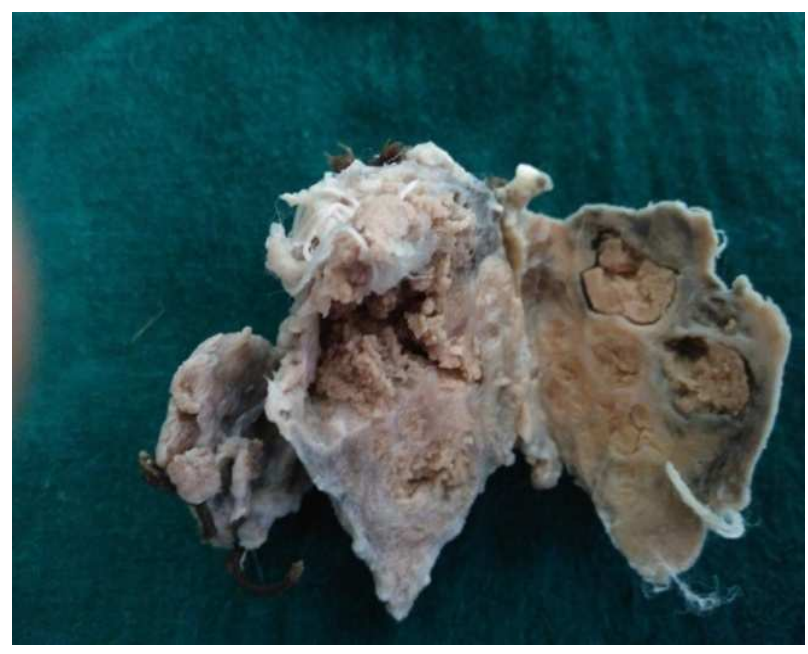

Fig. 4a- Gross specimen of papillary carcinoma

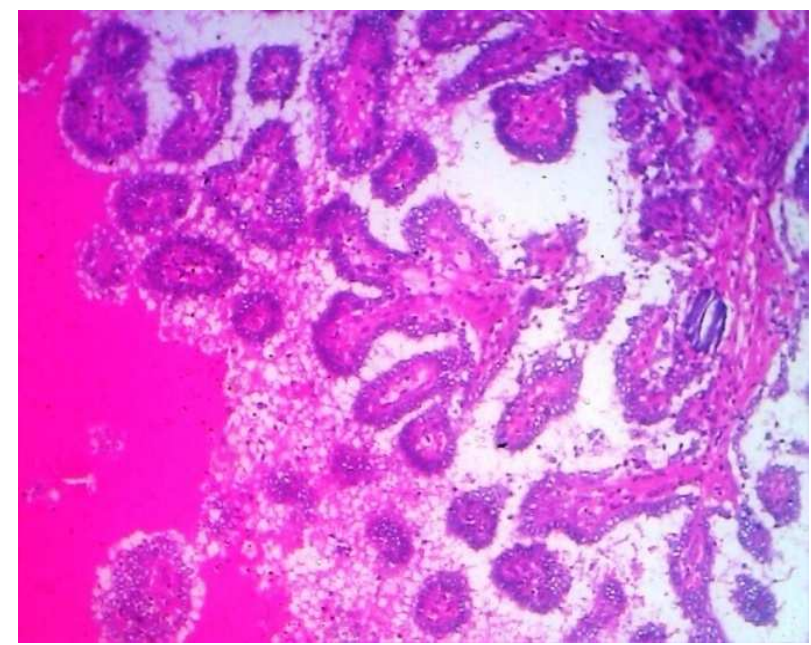

Fig-4b: Section showing features of papillary carcinoma with papillae lined by optically clear cuboidal cells. Note the psammoma body. (Hematoxylin and Eosin x100x)

The next most common neoplastic disorder was Follicular adenoma (18 cases, 07.50\%). This was followed by Follicular carcinoma (09 cases, $03.7 \%$ ), Hurthle cell adenoma (04 cases, $01.7 \%$ ) and Medullary carcinoma ( 1 case, $00.4 \%$ ).

\section{Discussion}

Thyroid disorders are common worldwide. Thyroidectomy is done since surgery may offer cure. Various studies conducted on thyroidectomy specimens in diverse parts of the world are documented in the literature [12-15]. Disorders affecting thyroid in different geographic areas of India are well documented [15-20]. In current study, as identical to many studies, the number of female patients were more than the male patients with female predominance of 8.2 : 1 . These results were in agreement with previous studies [15].

The non- neoplastic disorders (160 cases; $66.7 \%)$ were more than the neoplastic disorders (80 cases; $33.3 \%$ ). Similar results were found in other studies $[17,18]$.

Colloid goiter was the most common lesion in most of studies. In our study it accounted for $42.1 \%$. Similar results were found in other studies [17]. The age ranged from 21 to 83 years and the average age was 45 years. Females were commonly affected with female to male ratio 12.4: 1 . 


\section{Research Article}

The second most common non- neoplastic condition was Nodular Hashimoto thyroiditis (28 cases, 11.7\%). The incidence of combined Hashimoto thyroiditis with Multinodular goiter in one study was $0.55 \%$ [16]. Hashimoto thyroiditis with nodular hyperplasia is termed Nodular Hashimoto thyroiditis. The combination of Hashimoto thyroiditis and nodular hyperplasia, in all likelihood are pathogenetically related. Nodular Hashimoto thyroiditis would therefore seem more appropriate to designate this relatively common occurrence. The number of patients with Hashimoto thyroiditis was $17(7.1 \%)$. Similar results were found in other studies [17]. The number of patients with Lymphocytic thyroiditis was 4 cases (1.7\%) which were similar to results in one e study [18].

The number of patients with thyroglossal cyst was10 cases $(4.2 \%)$. Similar results were found in other studiesl [17]. The age group ranged from 2 to 46 years. The female to male ratio was $1: 1.5$ with a male preponderance. Similar male predominance with female to male ratio of $1: 1.37$ is reported [16].

The most common neoplasm of thyroid was Papillary carcinoma. It accounted for $57.5 \%$ of tumors of thyroid. There was an increased incidence of papillary carcinoma accounting for $19.2 \%$. Similar high incidence of $22.7 \%$ and $20.47 \%$ is found in other studies $[17,19]$.

The second neoplastic condition was follicular adenoma (22.5\%), followed by Follicular carcinoma (11.25\%) and Hurthle cell adenoma (5\%). Similar results in the incidence of Follicular adenoma and follicular carcinoma were found in other studies [17]. One case each of Medullary carcinoma, co-existent Papillary and follicular carcinoma and Synchronous Papillary carcinoma and Hurthle cell carcinoma is reported.

This study differs by other studies by an increased incidence of Nodular Hashimoto thyroiditis which may have been under diagnosed in many studies. There is an overall increased incidence of Autoimmune thyroiditis $(20.4 \%)$ including Nodular hashimoto thyroiditis (11.7\%), Hashimoto thyroiditis (7\%) and lymphocytic thyroiditis (1.7\%). Many authors have linked increased incidence of Hashimoto Thyroiditis, particularly in coastal areas, due to an excesses intake of iodine [2124]. Although essential for normal thyroid function, Iodine is an important precipitant of thyroid dysfunction. Excess iodine supplementation may be associated with thyroid autoimmunity. The possible mechanisms by which iodine may induce autoimmunity in the thyroid include direct stimulation of immune responses to the thyroid, direct toxic effects of iodine on thyrocytes via free oxygen radicals generation and increased immunogenicity of highly iodinated Thyroglobulin [25]. The incidence of Colloid goiter is less when compared to many studies [12-17] [19-20]. This may be due to the fact that the patients from coastal area may consume iodized salt and sea food rich in iodine which would have caused the mild decrease in the trend of colloid goiter. Thus the present study gives valuable epidemiological and demographic information about the various types of thyroid disorders that was incident over 6 years from 2010 to 2016 in a tertiary care hospital setup catering to coastal population, predominantly from Kochi area of Central Kerala, India.

\section{Conclusion}

The thyroid gland may be affected with various disorders. Thyroidectomy may have both therapeutic and diagnostic value. Non- neoplastic disorders outnumber the neoplastic disorders. Papillary carcinoma accounted for the most common neoplastic disorder affecting the thyroid gland. A higher incidence of autoimmune disorders affecting the thyroid gland in coastal areas may be due excess intake of iodine. Nodular Hashimoto thyroiditis may be considered in the differential diagnosis of thyroid lesions when there is Hashimoto thyroiditis with nodular hyperplasia.

Funding: Nil, Conflict of interest: None initiated, Permission from IRB: Yes

\section{References}

1. Mousavi SJ, Mikaili P, Mehdioghli R. Demographic and histopathological study of the thyroidopathies led to thyroid surgeries in Urmia Imam Hospital, Northwestern Iran. Annals of Biological Research 2011;2:5.

2. Anirban Mitra. Thyroid, In: Robbins Pathologic Basis of Disease. Cotran RS, Kumar V, Collins T editors. 8th ed. Philadelphia. WB Saunders Co; 2010. 1107-26.

3. Faquin WC. The thyroid gland: recurring problems in histologic and cytologic evaluation. Arch Pathol Lab Med. 2008 Apr;132(4):622-32. doi: 10.1043/1543-2165 (2008) 132[622:TTGRPI]2.0.CO;2. 


\section{Research Article}

4. Kochupillai N. Clinical endocrinology in India. Curr Sci 2000;79:1061-7.

5. Unnikrishnan AG, Menon UV. Thyroid disorders in India: An epidemiological perspective. Indian Journal of Endocrinology and Metabolism. 2011;15(2):78-81.

6. Park K. Iodine deficiency disorders. In: Park's text book of Preventive and Social Medicine. 19th ed. Jabalpur. Banarsidas Bhanot. 2007. 510-11.

7. Tsegaye B, Ergete W. Histopathologic pattern of thyroid disease. East Afr Med J.2003 Oct;80(10):525-8.

8. Lamfon HA. Thyroid Disorders in Makkah, Saudi Arabia. Ozean J Appl Sci 2008;1:55-8

9. World Health Organisation Classification of Tumours. In: DeLellis RA, Lloyd RV, Heitz P, Eng C, editors. Pathology and Genetics. Tumours of Endocrine Organs. Lyon: IARC Press; 2004. p. 50.

10. Kanapilly Francis Magdalene, Narayanan O.Navya. Cribriform-Morular Variant of a Papillary Carcinoma: A Case Report Middle East Journal of Cancer 2016; 7 (4): 209-213.

11. Narayanan O. Navya, Kanapilly F. Magdalene, Gopinath P. Satheesh. Synchronous Hurthle Cell Carcinoma and Papillary Carcinoma in a Patient with Hashimoto's Thyroiditis : A Rare Case Report. Middle East Journal of Cancer 2014; 5(4): 221-224.

12. Albasri A, Sawaf Z, Hussainy AS, Alhujaily A. Histopathological patterns of thyroid disease in AlMadinah region of Saudi Arabia. Asian Pac J Cancer Prev. 2014;15(14):5565-70.

13. Ijomone EA, Duduyemi BM, Udoye E, Nwosu SO. Histopathological review of thyroid diseases in southern Nigeria-a ten year retrospective study . Journal of Medicine and Medical Sciences 2014; 5(6) pp. 127-132.

14. Raphael Solomon, Yawale Iliyasu, AZ Mohammed. Histopathological pattern of thyroid lesions in Kano, Nigeria: A 10-year retrospective review (2002-2011). Niger J Basic Clin Sci 2015;12:55-60.

15.Champa Sushel, Tariq Wahab Khanzada, Imrana Zulfikar, Abdul Samad. Histopathological pattern of diagnoses in patients undergoing thyroid operations RMJ. 2009; 34(1): 14-16.

16. Ashwini Kolur, Anitha B, Letha P, Trupti Joshi, Jayasree, Samith Ahmed, Harish Naik. Pattern of thyroid disorder in thyroidectomy specimen. International Journal of Medical Science and Public Health. 2014; 12( 3):1446-1448

17. Indhuja Bharathidhasan, Mangala Goneppanavar, Rajendra Singh Dhaka. Changing trends in the incidence of thyroid lesions in coastal regions of South India. International Journal of Health Sciences \& Research 2015.5(6):134-140.

18. Ahmed Z, Chaudhary R, Umaru N. Study of prevalence of thyroid lesions in coastal region of Karnataka. Journal of Evolution of Medical and Dental Sciences 2013; 2(36):6995-7002.

19. Narayanappa Shiroorkar Pradeepkumar, Reecha Singh, Noyal Mariya Joseph Emerging trends in thyroid diseases in tsunami hit coastal areas of Puducherry and Cuddalore, India. Journal of Evolution of Medical and Dental Sciences 2012; 1(5): 857-863.

20. Subhabrata Sengupta, Isha Preet Tuli, Binayak Baruah, Santosh Prasad Kesari, Bhargav Ilapakurty, Amlan Gupta. Spectrum of goitrous lesions in patients at a tertiary care center of Sikkim. Sahel Medical Journal 2014;17( 3): 112-116.

21. Zois C, Stavrou I, Kalogera C, Svarna E, Dimoliatis I, Seferiadis K, et al. High prevalence of autoimmune thyroiditis in schoolchildren after elimination of iodine deficiency in northwestern Greece. Thyroid 2003; 13:485-9.

22. Vanderpump MP, Tunbridge WM, French JM, Appleton D, Bates D, Clark F, Grimley Evans J, Hasan DM, Rodgers H, Tunbridge F, et al. The incidence of thyroid disorders in the community: a twenty-year follow-up of the Whickham Survey. Clin Endocrinol (Oxf). 1995 Jul;43(1):55-68.

23. Jayaram G, Marwaha RK, Gupta RK, Sharma SK. Cytomorphologic aspects of thyroiditis. A study of 51 cases with functional, immunologic and ultrasonographic data. Acta Cytol. 1987 Nov-Dec;31 (6): 687-93. 
24. Li Y, Teng D, Shan Z, Teng X, Guan H, Yu X, Fan C, Chong W, Yang F, Dai H, Gu X, Yu Y, Mao J, Zhao D, Li J, Chen Y, Yang R, Li C, Teng W. Antithyroperoxidase and antithyroglobulin antibodies in a five-year follow-up survey of populations with different iodine intakes. J Clin Endocrinol Metab. 2008
May;93(5):1751-7. doi: 10.1210/jc.2007-2368. Epub 2008 Feb 12.

25. Papanastasiou L, Vatalas IA, Koutras DA, Mastorakos G. Thyroid autoimmunity in the current iodine environment. Thyroid. 2007 Aug;17(8):729-39.

\section{How to cite this article?}

K.F. Magdalene, Jose Swetha, Navya Narayanan, B Sumangala. Histopathological study of thyroid lesions in a tertiary care center in coastal belt of South India. Trop J Path Micro 2017;3(1):77-83.doi: 10.17511/jopm.2017.i1.14. 